\title{
The Evolution of Green Shipping Practices Adoption in the International Maritime Industry
}

\author{
Alam Md Moshiul ${ }^{1}$, Roslina Mohammad ${ }^{1}$, Hira Fariha Anjum ${ }^{2}$, \\ Aliya Yesmin ${ }^{3}$, Shreeshivadasan Chelliapan ${ }^{1}$ \\ ${ }^{1}$ Razak Faculty of Technology and Informatics, Universiti Teknologi Malaysia, Jalan Sultan Yahya Petra, \\ 54100, Kuala Lumpur, Malaysia \\ ${ }^{2}$ Azman Hashim International Business School, Universiti Teknologi Malaysia, Jalan Sultan Yahya Petra, \\ 54100, Kuala Lumpur, Malaysia \\ ${ }^{3}$ Azman Hashim International Business School, Universiti Teknologi Malaysia, 81310, Skudai, Johor, Malaysia
}

\begin{abstract}
Seaborne trade exhibits a continual expansion with technological advancement, reportedly 10.7 billion tons in 2017 , with a $3.8 \%$ growth annually. It is forecast to double in the next two decades (UNCTAD, 2018). The International Maritime Organization (IMO) is persistently heading to stricter regulatory amendments to steer shipping towards a greener and more sustainable future. Therefore, green shipping has drawn enormous interest from both academia and researchers. This paper summarizes a comprehensive bibliometric analysis aiming to understand the development of research trends in this area and suggest future research. Most of the research is focused on air pollution, practical operation or technical measures, recycling for GSP in the shipping sector. The theoretical approach to GSP and its concept is yet to be crystalline for the marine industry.

According to existing research, further study is required to establish a GSP construct and propose pollution abatement technical solutions with a comprehensive evaluating tool. Besides, scholars from
\end{abstract}

DOI: $10.18421 /$ TEM103-15

https://doi.org/10.18421/TEM103-15

Corresponding author: Shreeshivadasan Chelliapan, Razak Faculty of Technology and Informatics, Universiti Teknologi Malaysia, Jalan Sultan Yahya Petra, 54100, Kuala Lumpur, Malaysia.

Email: shreeshivadasan.kl@utm.my

Received: 23 April 2021.

Revised: 10 July 2021.

Accepted: 17 July 2021.

Published: 27 August 2021.

(c) BY-NC-ND (C) 2021 Alam Md Moshiul et al; published by UIKTEN. This work is licensed under the Creative Commons Attribution-NonCommercial-NoDerivs 4.0 License.

The article is published with Open Access at www.temjournal.com different territories may collaboratively suggest setting up standards and legislation of GSP for the life cycle of the ship to achieve an ever-sustainable maritime transport industry worldwide.

Keywords - Bibliometric analysis, emission, green shipping, pollution, VOSviewer.

\section{Introduction}

International shipping is recognized as the backbone of global trade and economy by transporting over 80 percent of merchandise through seaports worldwide by volume, which is more than 70 percent of global trade value [1]. Seaborne shipping demand continues to grow because of its competitive freight and its capacity to move an enormous cargo volume in an eco-friendly and safe manner compared to other transport modes. While it has a very positive influence on global economic development, in terms of pollution, it harms the environment and is traditionally considered a significant source of air and water pollution. Shipping accounts for annual NOx, Sox, and $\mathrm{CO} 2$ emission from anthropogenic sources at 15\%, 13\%, and 3\%, respectively, recorded as ship emitted air pollutants from 2007 to 2012 globally [2]. Ships pollute water by discharging bilge, oil, sewage, garbage to the sea. The exchange of ballast water causes ecological damage by transferring invasive aquatic species. The International Maritime Organisation (IMO), a global regulatory body for shipping, adopted the International Conventions for the Prevention of Pollution from Ships, known as MARPOL. It has six regulatory annexes in force to prevent pollution by oil, noxious liquid, harmful substances, sewage, garbage, and air pollution from ships, respectively. IMO is gradually intensifying environmental regulations. IMO's strategic roadmap for the maritime industry for addressing greenhouse 
gas abatement is to construct ships with an immediate reduction in GHG emissions of $15 \%$, then $20 \%$ by 2020 , and $30 \%$ by 2025 [3]. Additionally, at the Marine Environment Protection Committee's 62nd General Meeting in July 2012, IMO has revised MARPOL Annex VI to reduce carbon dioxide (CO2) emissions from ships by 2030 [4]. According to the Paris Agreement, IMO adopted a comprehensive strategy of phasing out $\mathrm{CO} 2$ emissions across the shipping sector, including a $50 \%$ total reduction by 2050 [5].

The shipping industry is currently undergoing an expanded strain to comply with progressively stringent environmental regulations aiming to be cleaner and greener in their activities. Consequently, shipping firms have been gradually promoting the adoption of green shipping practices [6]. GSP is recognized to be effective with insignificant ecological damage [2]. It is presumed to be an efficient approach for achieving a global transition towards a low-carbon, green economy by controlling emissions and pollution. Green shipping has been a wide-reaching concern for the maritime transport industry and has drawn the researchers' attention since 2010. Scientific publication numbers have grown significantly after that. The bibliometric study facilitates researchers in plotting research trends in a specific field of interest [7].

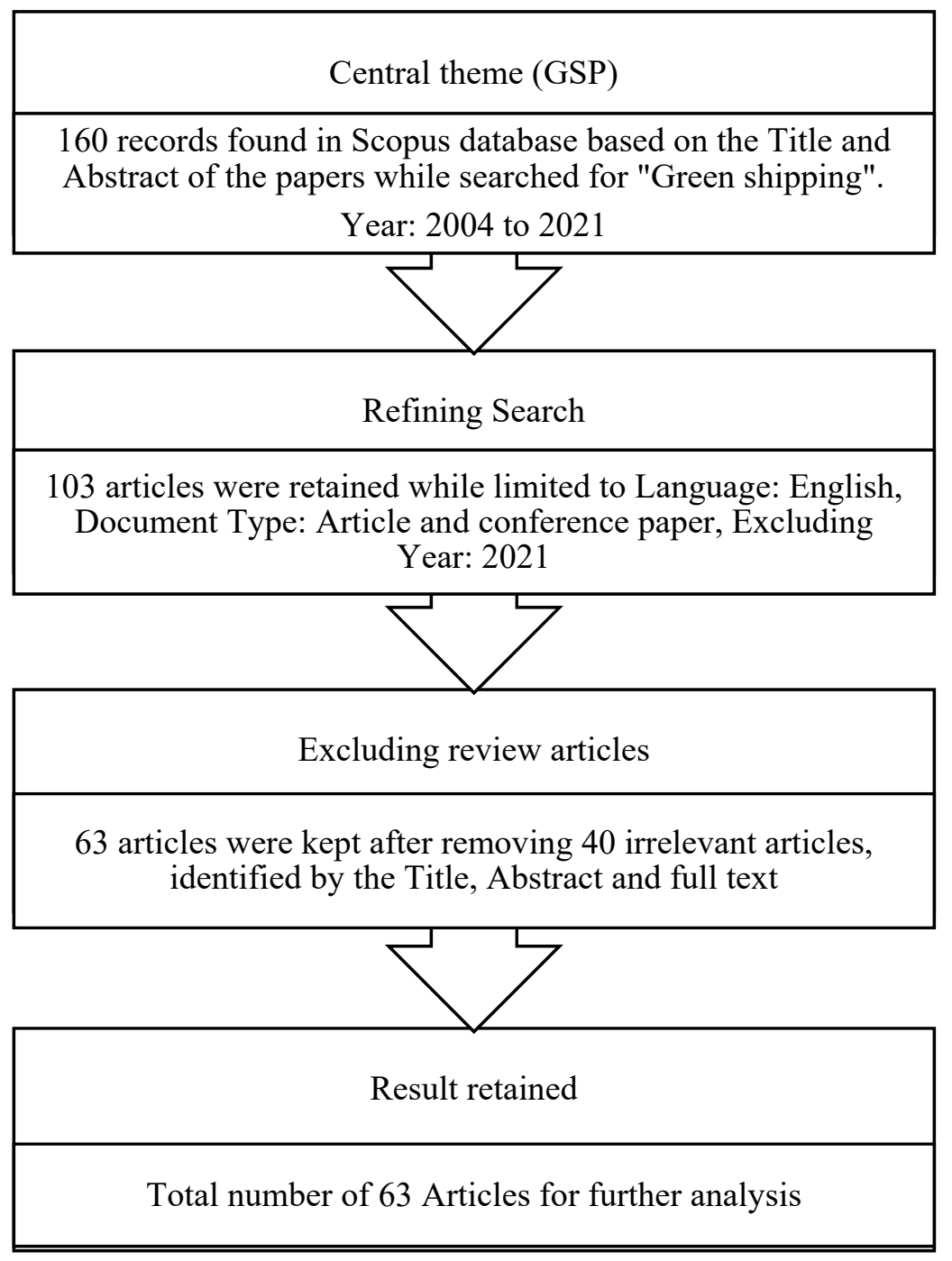

Figure 1. Flow diagram of data collection for search theme

\section{Methods}

The research area on GSP adoption in the maritime industry is analyzed using this study's bibliometric approach. It is a mechanistic method to determine global research trends in a specific field of interestbased on published scholarly articles in a scientific database. This analytic approach intends to evaluate and critique the current research status in the green shipping era. This bibliometric assessment aims to outline the evolution and challenges of interest through published research articles in the subject area. The bibliometric study offers future directions for further study in that specific area [8]. 


\subsection{Data Sourcing and Research Strategy}

Scopus is a core scientific database recognized by Elsevier and has around has around 70 million articles [9], [10]. This study evaluates data retrieved from the Scopus database. The data mining process was conducted from February 20th to 22nd in 2021. Researchers' area of interest is green shipping practice adoption in the maritime industry. Hence query string applied for the search was: TITLE-ABSKEY ("Green Shipping") AND (LIMIT-TO (DOCTYPE, "ar")) AND (LIMIT-TO(LANGUAGE, "English")) AND (EXCLUDE (PUBYEAR, 2021)). This search stemmed from a total of 103 articles and conference papers. The oldest article was from the year 2007 and the latest one from 2021. The current year 2021 articles were excluded as they are yet to be completed at the time of writing. Systematic review papers and some other articles were excluded after appraising abstract, keywords, and full-text owing to the terms cited. Few articles were rejected due to a lack of information on the author's name and abstract. A total of 40 articles were potentially unrelated to this study, which was listed and inserted in the Scopus search string to confirm the exclusion of those documents from the CSV file, as shown in Figure 1. Subsequently, a total of 63 articles were retained for analysis.

\subsection{Bibliometric Maps}

This bibliometric study used the VOSviewer software version 1.6.14 as an analytic tool. The Centre for Science and Technology Studies, Leiden University, The Netherlands developed this software. It is used for constructing and imaging bibliometric maps. Hence, author keywords, citation details, countries, and bibliographical data were extracted from the Scopus database to create and visualize bibliometric maps. Information extracted from the Scopus database (CSV format) for 63 selected articles were exported to "VOSviewer" for bibliometric map creation and analysis.

\subsubsection{Co-Authorship Analysis}

Co-authorship refers to authors joint publication [9], [11]. The bibliometric network of VOSviewer represents the linkage among scholars, universities, countries, or regions depending on the number of papers published together authors in the coauthorship investigation section. VOSviewer listed 170 authors. Figure 2 exhibits 18 authors of 170 who have an affiliation with each other. The visualization map comprises 54 links and a total of 56 link strengths distributed in 3 clusters. "A cluster is a set of closely related nodes. Each node in a network is assigned to exactly one cluster. The number of clusters is determined by a resolution parameter" [12]. For instance, authors Kanwllos F. and Spathis D. both (as indicated in the VOSviewer overlay visualization plot on Figure 2) from cluster 2 having 11 links with a total strength of 12 , and the average year of publication is 2017.50 (mid-2017) with two articles. Among them, co-authorship link strength is 2. It means individual link strength and co-authorship link strength among the two authors are different phenomena.

The co-authorship analysis included 25 countries affiliated with 170 authors. Setting a minimum number to one of co-authorship from a country, 15 countries among 25 met the thresholds. Figure 3 demonstrates that these 15 countries are affiliated with 23 links and a link strength of 32 . The affiliated countries were clustered into six in terms of coauthorship analysis - cluster 1 (China, Hong Kong, Singapore, United States), Cluster 2 (Belgium, Greece, Spain), Cluster 3 (Denmark, Germany), Cluster 4 (Italy, Netherlands), Cluster 5 (Canada, Norway) and Cluster 6 (Sweden, United Kingdom). The link strength between Norway and Germany is 4 . Between Germany and China, the link strength is 1 . The link value is equally proportionate to the numerical link strength; a higher link value means higher link strength [9], [12].

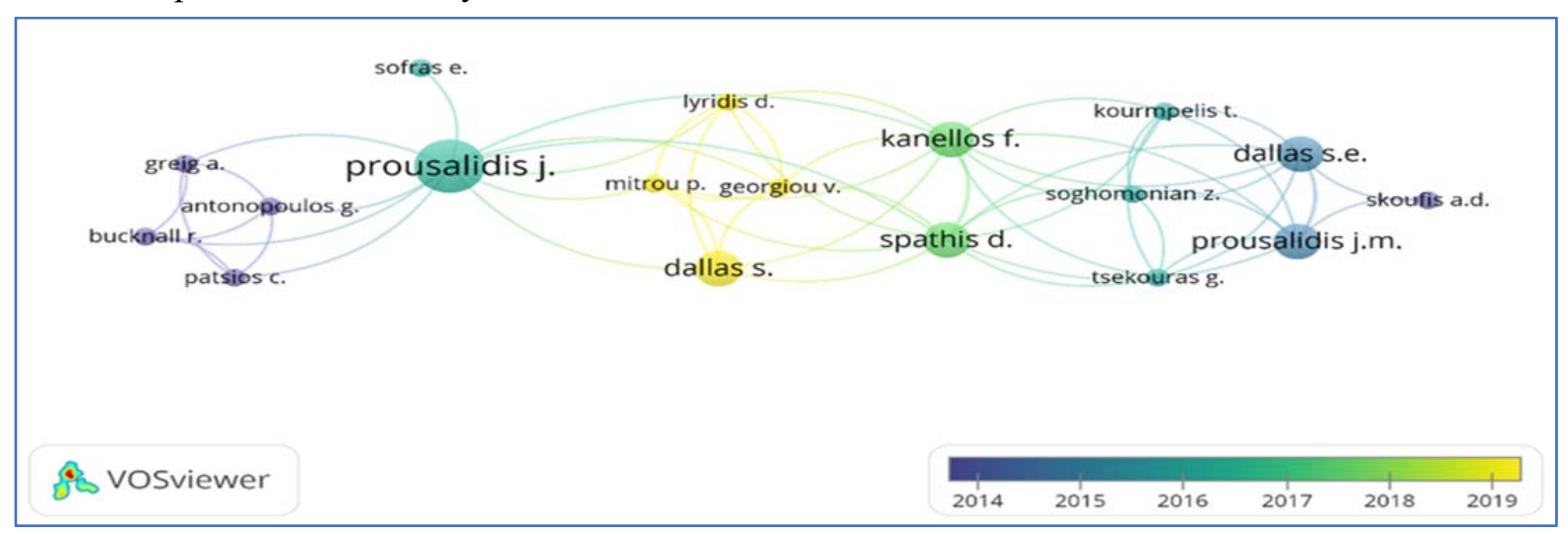

Figure 2. Co-authorship bibliometric map using author names from VOSviewer 


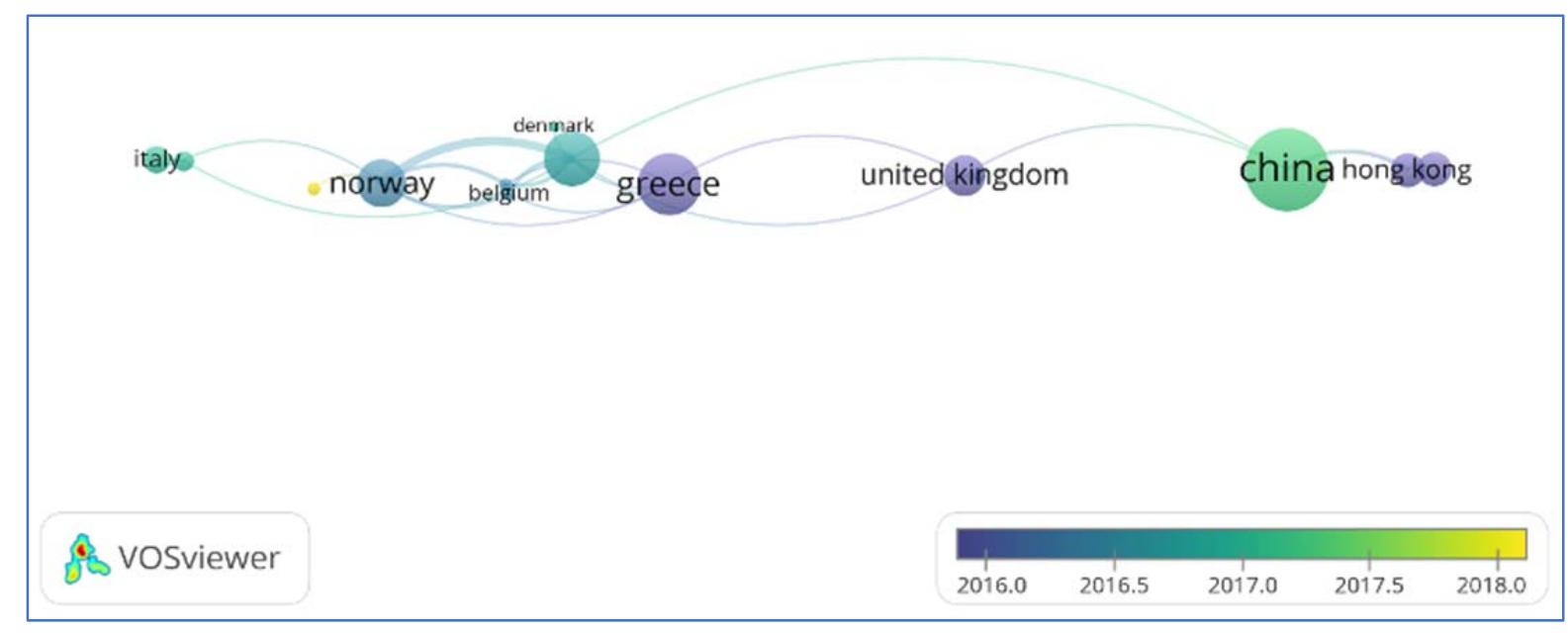

Figure 3. Bibliometric map of co-authorship from VOSviewer using country

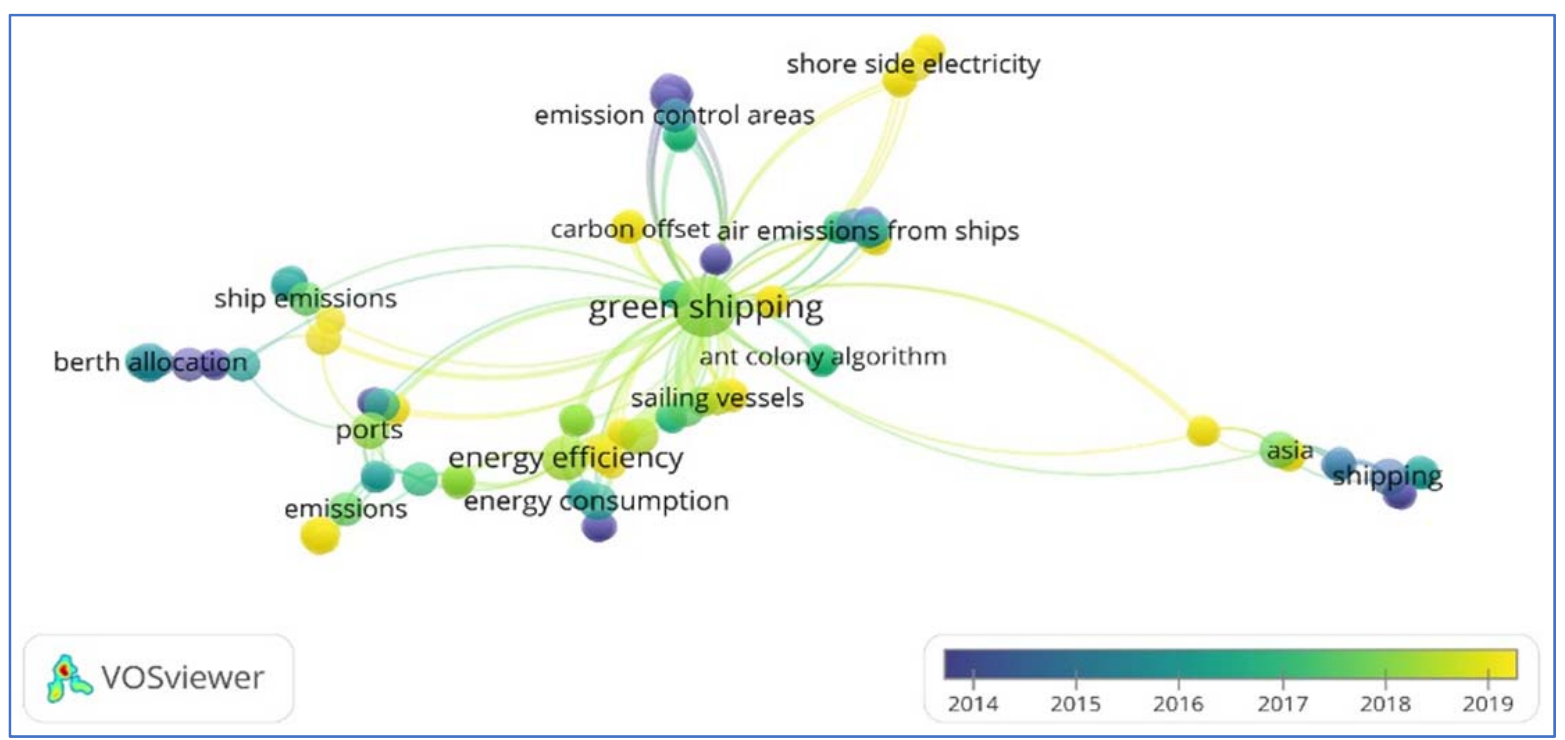

Figure 4. Co-occurrence of author keywords analysis from VOSviewer

\subsubsection{Analysis of Co-Occurrence of Author Keywords}

Author keyword's Co-occurrence analyses explore frequently used keywords which usually can be seen below the introduction section of articles [11]. This study analyzed 225 author's keywords from 63 articles, where more massive sets of related items were 147 . Notably, only the authors' keywords were taken into consideration for analysis, not index keywords. The minimum numbers of co-occurrence could be set highest to 3 for this analysis based on the information transmitted to VOSviewer. Only 8 (3\%) author's keywords met the threshold when set to 3 . With a minimum setting of c-occurrence 2 , a total of 33 keywords $(13 \%)$ met the threshold. Figure 4 illustrates the co-occurrence of the authors' keywords setting at least the number of 1 .

Few keywords share the same meaning, such as ECA, ECA's, and emission control areas. During analysis, researchers removed keywords that portray similar meanings. Other than green shipping (21 times), the ten most frequently used authors' keywords are energy efficiency (6 times), shipping, sustainability, heterogeneous pollution, energy consumption, ports (3 times each), followed by emission control areas, emission, air emission from the ship, environment (2 times each). "Keyword analysis of publications provides an effective way not only to investigate the knowledge structure of research domains but also to explore the developing trends within domains." [13]. Author's keyword analysis findings conclude that emission pollutants from engine power generation of the merchant ships operating with energy-efficient or low-carbon fuels may lead to green and sustainable maritime transport. Furthermore, several articles reflect distinct subtopics of green shipping, technology, operational measures, profitability, owner or management, or user's acceptance and offer scope for further research in this arena. 


\section{Findings and Analysis}

\subsection{Research Interest Growth Mapping}

Scholarly articles on green shipping practices (GSP) in the international maritime industry that have been published per year in Scopus indexed journals from 2007 to 2019 are illustrated in Figure 5. 13 papers have been published in 2020, which were irrelevant to this study and the year of 2021 is yet to be completed. Therefore Figure 5 presents data until 2019. Although eco-friendly marine research has a deep historical foundation, the concept of green shipping practice adoption in the industry was first introduced in 2007 (Green shipping conference 2006, Copenhagen; Author: Greenway A.) Scholars started to explore GSP appropriation potential within shipping firms after that. The Scopus database evidenced a successive increment of qualitative, quantitative, and case study-based research articles on GSP from 2010.
This significance might be attributed to concerns growing on the ecological impact of shipping activities.

Additionally, the global maritime regulatory body, the International Maritime Organisation (IMO), enforces environmental pollution abatement regulations through flag states and port states. Development of technology, upgradation of marine engines, inventions of alternate eco-friendly fuels and operational measures, and the accessibility of increased data, contemporary novel research methods, and computing tools escalate the researchers' interest in GSP in the shipping sector. A significant rise in research trends in recent years proves that GSP will remain relevant for future maritime transport sustainability. GSP adoption in the maritime transport sector is still in the embryonic stage, which requires research gaps to be addressed and specific studies in the sea transport domain since green technologies are evolving with the sustainability concept.

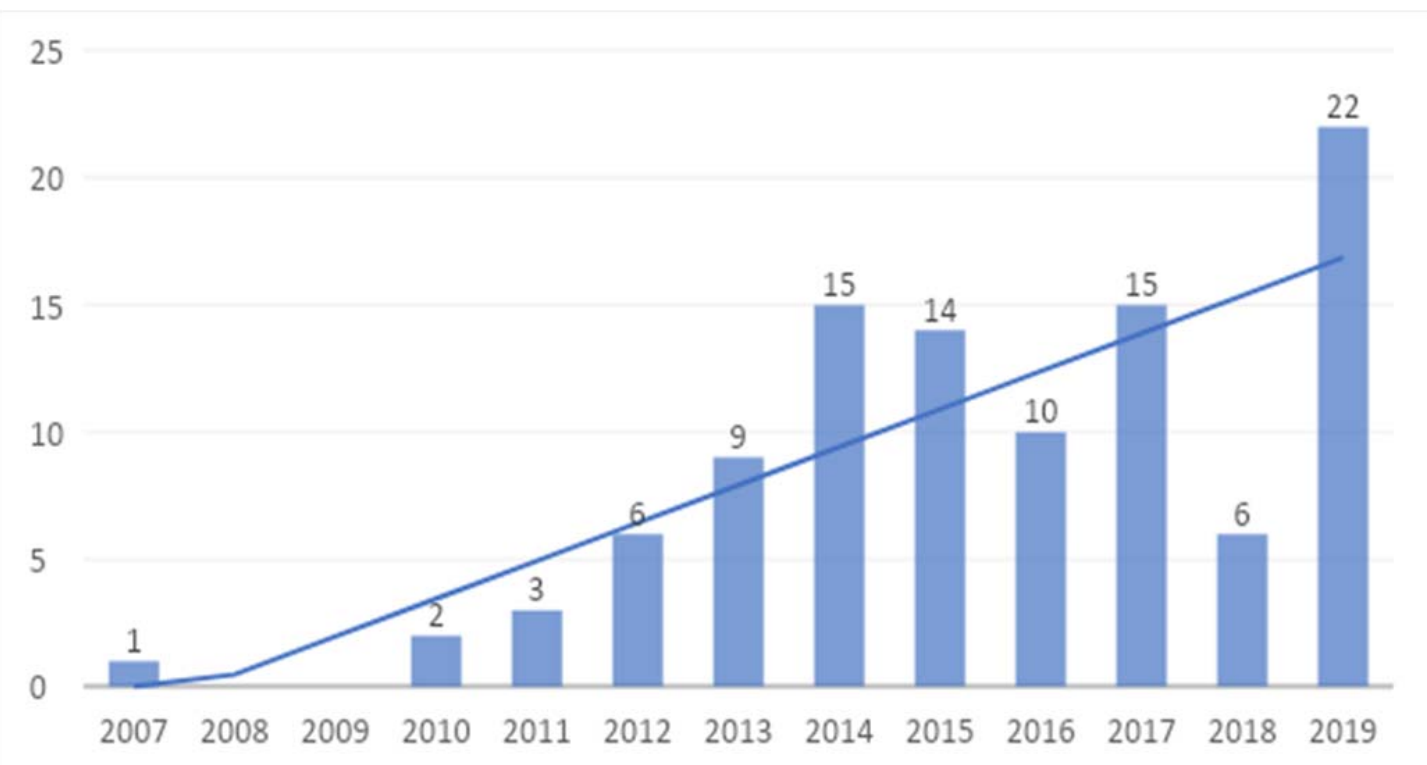

Figure 5. Documents published on GSP from 2007 to 2019 in the Scopus database

The analysis considered the papers which are categorized as qualitative, quantitative, or case study. It is found that the majority of the published research papers were based on qualitative (49 papers, 78\%) research method followed by $14 \%$ (9 papers) case studies while quantitative papers were only $8 \%$ ( 5 papers). This indicates that total number of studies is minimal, and more is required. Additionally, no studies are using a mixed-method to validate the outcomes.

Depending on the shipping industry's nature, studies should focus on the real-world problem in a natural setting to understand the underlying causes of stakeholders' behavior, industrial and organizational environment. The qualitative method aims to deliver an exhaustive understanding of "real-world problems" [14]. Hence qualitative scholars emphasize perceived 'reality' depending on historical, socio-cultural, and individual contexts. While taking organizational aspects into account for real problem solving, generalization is not required; consequently, quantitative study is not applicable. Hence, depending on research questions, a mixed-method approach can be applied for the in-depth understanding of the phenomenon of interest [15]. 
Table 1. Most distinguished journals and publishers

\begin{tabular}{|c|c|c|c|c|}
\hline No & Journals & Publisher & $\begin{array}{c}\text { Number of } \\
\text { publications }\end{array}$ & $\begin{array}{c}\text { Cite Score } \\
(2018)\end{array}$ \\
\hline 1 & Naval Architects & Royal Institution of Naval Architects & 11 & 0.01 \\
\hline 2 & $\begin{array}{c}\text { Transportation Research Part D } \\
\text { Transport and Environment }\end{array}$ & Elsevier & 11 & 5.07 \\
\hline 3 & Maritime Policy and Management & Taylor \& Francis & 4 & 3.22 \\
\hline 4 & Polish Maritime Research & Walter de Gruyter & 4 & 1.48 \\
\hline 5 & Ocean Engineering & Elsevier & 3 & 3.60 \\
\hline
\end{tabular}

\subsection{Journals}

Journals that published articles on green shipping were identified through this analysis. This also assists the researcher in comprehending the motivation of each article. Table 1 represents the five most distinguished journals which publish articles on GSP from 2007 to 2019 .

\subsection{Leading Institutions and Territory or Countries}

Altogether, 80 institutions contributed to this field of research. Figure 6 illustrates the number of articles published by the most prominent ten institutions. Hong Kong Polytechnic University ranked first with ten articles; the National Technological university of Athens ranked second with nine articles. The Gdańsk University of Technology and DNV GL AS each have five publications. Other institutions have three or fewer publications.

The publication outcome measurement can be different depending on the institute's specific requirements. Consequently, the number of articles may fluctuate among institutions or universities. Furthermore, institutes' supporting mechanism in finance and human resources (H.R.) also differs between institutes. Therefore, high-impact articles' quantity closely ties with the institutions that deliver suitable reward appraisal and HR-related support for research. Consequently, institutes that nurture a positive and supportive environment (financial and others) for research tend to have a higher quantity of high-impact articles.

Figure 7 denotes the most prominent ten countries and the number of published articles on GSP. China is leading the list with 14 publications, followed by Germany's 11 publications; Greece and Hong Kong published ten articles. Other countries' publication status is as follows; the United Kingdom published nine articles, Norway eight articles, and Poland six articles. The list ends with Canada, Denmark, and Singapore, where each of the countries published five articles, respectively. China has the highest number of publications since quite a few SJR journals originate from China. All the listed countries have extensive involvement in business related to the shipping industry.

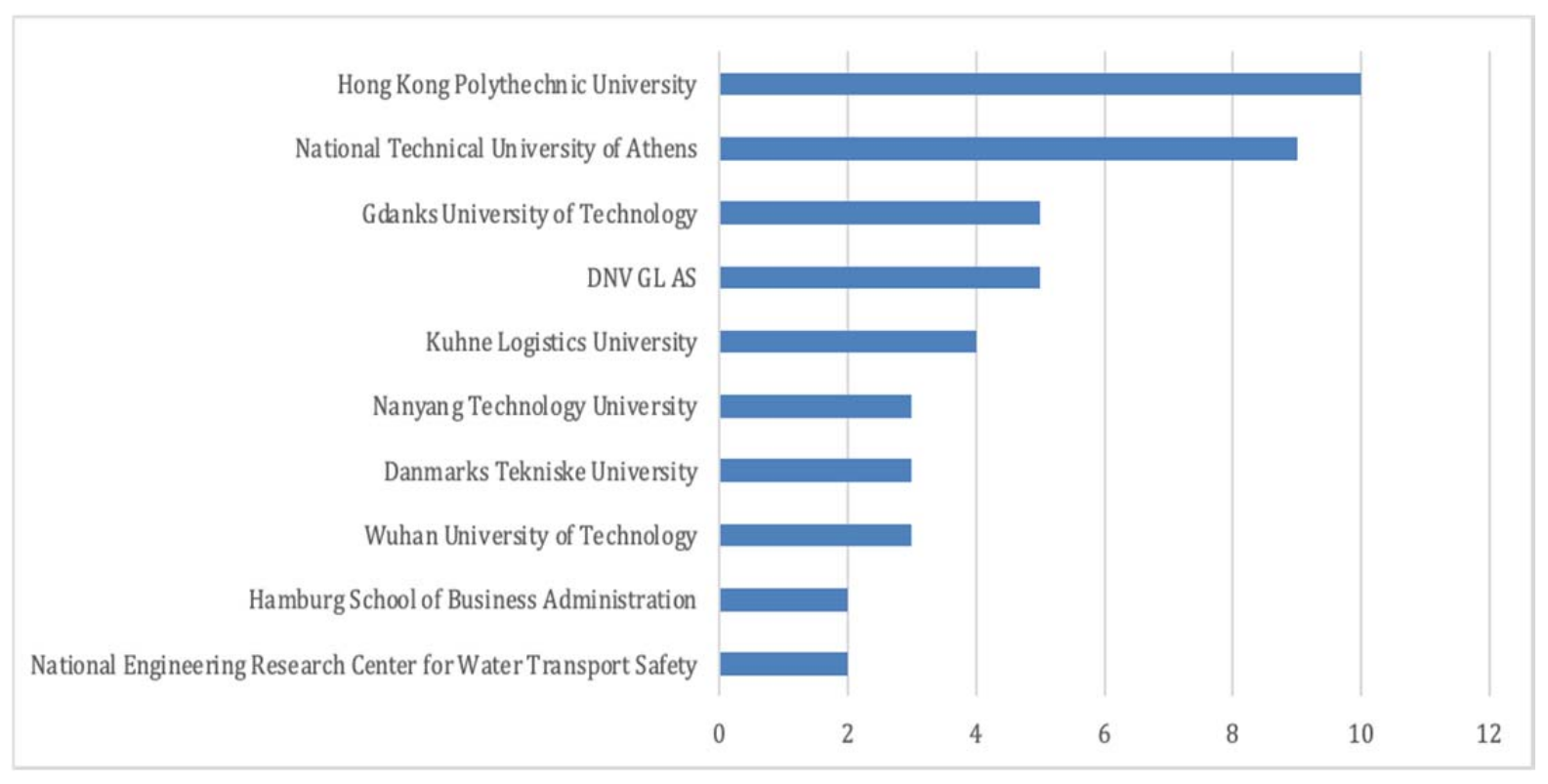

Figure 6. Number of articles published by the most prominent10 institutions 


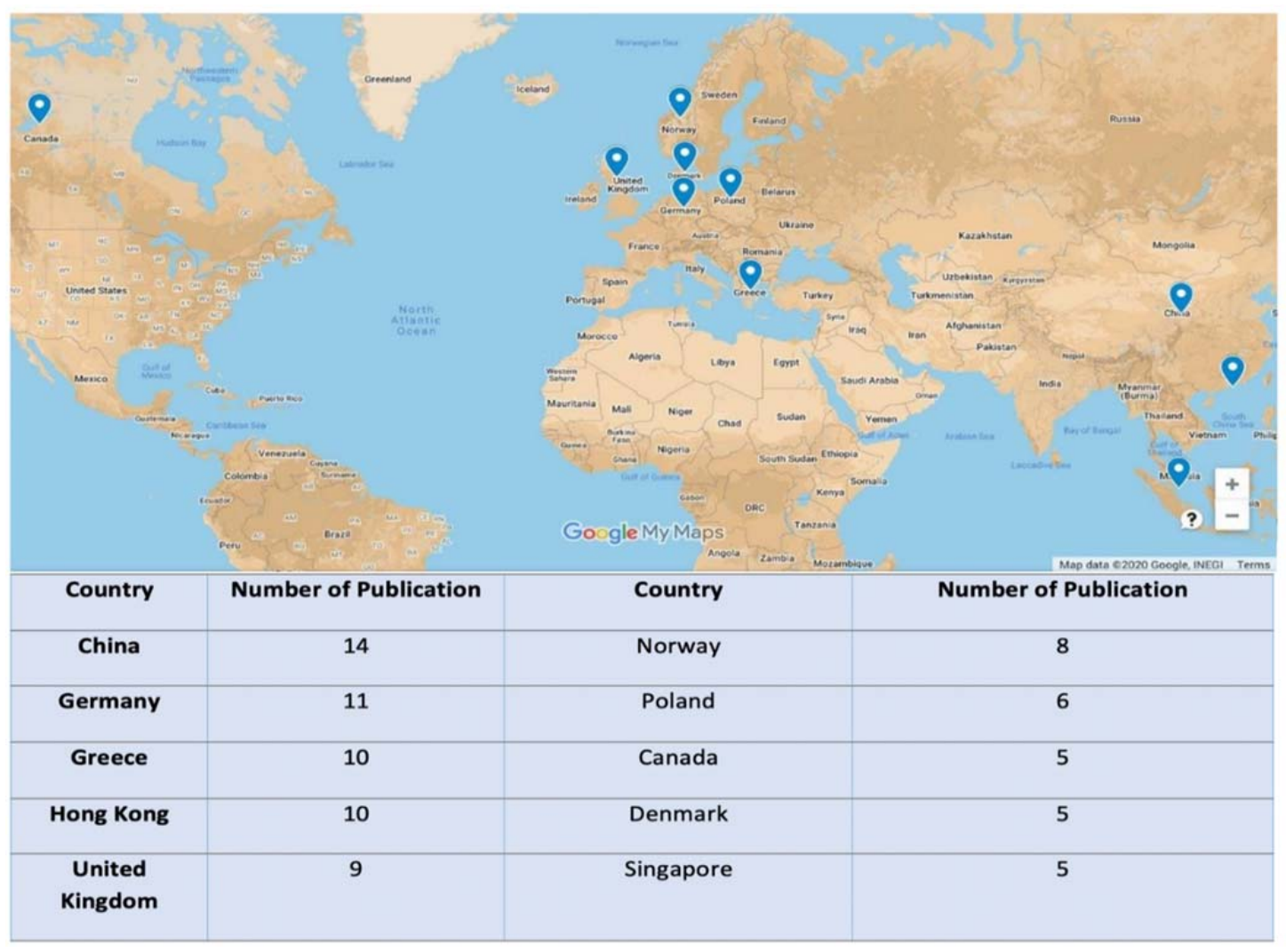

Figure 7. Most prominent ten countries and number of published articles on GSP

\subsection{Leading Authors}

The most prominent 20 authors of GSP are affiliated to 10 different nations, as shown in Table 2 . This study ranked authors based on data collected from Scopus. Country names with numerous authors affiliated are as follows; Hong Kong (4 authors), Germany and Greece (3 authors of each country), Poland, China and Netherlands (2 authors), Denmark, Belgium, Norway, Canada (1 author, each country). The authors' first articles were published from 1978 to 2019. Author Cheng, Tai Chiu Edwin from Hong Kong, ranked first depending on the number of publications. He has a total of 806 articles since 1984, with 70 h-index and 22,831 citations. He is currently affiliated with Hong Kong Polytechnic University, Hong Kong.

Table 2. 20 Most Prominent Authors

\begin{tabular}{|c|l|c|c|c|c|c|c|c|}
\hline No & \multicolumn{1}{|c|}{ Author } & \multicolumn{1}{|c|}{$\begin{array}{c}\text { Scopus } \\
\text { Author ID }\end{array}$} & $\begin{array}{c}\text { Year of first } \\
\text { Journal by } \\
\text { author }\end{array}$ & $\begin{array}{c}\text { Total } \\
\text { publication }\end{array}$ & $\begin{array}{c}h- \\
\text { index }\end{array}$ & $\begin{array}{c}\text { Total } \\
\text { citations }\end{array}$ & Current affiliation & Country \\
\hline 1 & $\begin{array}{l}\text { Cheng, Tai Chiu } \\
\text { Edwin }\end{array}$ & 13302593800 & 1984 & 806 & 70 & 22,831 & $\begin{array}{l}\text { Hong Kong } \\
\text { Polytechnic } \\
\text { University }\end{array}$ & $\begin{array}{c}\text { Hong } \\
\text { Kong }\end{array}$ \\
\hline 2 & Litwin, Wojciech & 24175616500 & 2005 & 33 & 10 & 276 & $\begin{array}{l}\text { Gdańsk University } \\
\text { of Technology }\end{array}$ & Poland \\
\hline 3 & Lun, Y.H. Venus & 16029106700 & 2007 & 57 & 20 & 1,167 & $\begin{array}{l}\text { Hong Kong } \\
\text { Polytechnic } \\
\text { University }\end{array}$ & $\begin{array}{l}\text { Hong } \\
\text { Kong }\end{array}$ \\
\hline 4 & $\begin{array}{l}\text { Wong, Christina } \\
\text { W. Y. }\end{array}$ & 7404954357 & 2003 & 79 & 29 & 2,844 & $\begin{array}{l}\text { Hong Kong } \\
\text { Polytechnic } \\
\text { University }\end{array}$ & $\begin{array}{l}\text { Hong } \\
\text { Kong }\end{array}$ \\
\hline 5 & Acciaro, Michele & 25925749500 & 2008 & 26 & 10 & 428 & $\begin{array}{l}\text { Kühne Logistics } \\
\text { University }\end{array}$ & Germany \\
\hline 6 & Lai, Kee hung & 57205344886 & 1986 & 173 & 53 & 10,516 & $\begin{array}{l}\text { Hong Kong } \\
\text { Polytechnic } \\
\text { University }\end{array}$ & $\begin{array}{l}\text { Hong } \\
\text { Kong }\end{array}$ \\
\hline 7 & $\begin{array}{l}\text { Psaraftis, } \\
\text { Harilaos N. }\end{array}$ & 57119450500 & 1978 & 136 & 27 & 3,398 & $\begin{array}{l}\text { Danmarks Tekniske } \\
\text { Universitet }\end{array}$ & Denmark \\
\hline
\end{tabular}




\begin{tabular}{|c|c|c|c|c|c|c|c|c|}
\hline 8 & $\begin{array}{l}\text { Prousalidis, John } \\
\text { M. }\end{array}$ & 36902044300 & 1993 & 64 & 11 & 418 & $\begin{array}{l}\text { National Technical } \\
\text { University of Athens }\end{array}$ & Greece \\
\hline 9 & $\begin{array}{l}\text { Cura-Hochbaum, } \\
\text { Andrés }\end{array}$ & 56912334000 & 2015 & 7 & 2 & 28 & $\begin{array}{l}\text { Technical University } \\
\text { of Berlin }\end{array}$ & Germany \\
\hline 10 & $\begin{array}{l}\text { Dallas, Stefanos } \\
\text { E. }\end{array}$ & 36514336900 & 2014 & 12 & 3 & 23 & $\begin{array}{l}\text { Logistic Command, } \\
\text { Athens }\end{array}$ & Greece \\
\hline 11 & $\begin{array}{l}\text { Delefortrie, } \\
\text { Guillaume }\end{array}$ & 10739448300 & 2003 & 31 & 10 & 191 & $\begin{array}{l}\text { Universiteit Gent, } \\
\text { Ghent, }\end{array}$ & Belgium \\
\hline 12 & Fu, Shanshan & 9335192400 & 2011 & 29 & 7 & 125 & $\begin{array}{l}\text { Shanghai Maritime } \\
\text { University }\end{array}$ & China \\
\hline 13 & $\begin{array}{l}\text { Huijsmans, René } \\
\text { H.M. }\end{array}$ & 6701318835 & 1980 & 113 & 15 & 904 & $\begin{array}{l}\text { Delft University of } \\
\text { Technology }\end{array}$ & Netherlands \\
\hline 14 & $\begin{array}{l}\text { Jia, Haiying } \\
\text { Bergen, }\end{array}$ & 57194822166 & 2004 & 21 & 10 & 178 & $\begin{array}{l}\text { NHH Norwegian } \\
\text { School of } \\
\text { Economics }\end{array}$ & Norway \\
\hline 15 & Jin, Xiaochuang & 56949533700 & 2015 & 4 & 1 & 4 & Nankai University & China \\
\hline 16 & $\begin{array}{l}\text { Kanellos, Fotis } \\
\text { D. }\end{array}$ & 6506656620 & 2000 & 60 & 16 & 918 & $\begin{array}{l}\text { Technical University } \\
\text { of Crete }\end{array}$ & Greece \\
\hline 17 & $\begin{array}{l}\text { Keuning, Jan } \\
\text { Alexander }\end{array}$ & 7003605441 & 1980 & 32 & 7 & 119 & $\begin{array}{l}\text { Delft University of } \\
\text { Technology }\end{array}$ & Netherlands \\
\hline 18 & $\begin{array}{l}\text { Kunicka, } \\
\text { Magdalena }\end{array}$ & 57210143567 & 2019 & 2 & 1 & 2 & $\begin{array}{l}\text { Gdańsk University } \\
\text { of Technology }\end{array}$ & Poland \\
\hline 19 & $\begin{array}{l}\text { Lengwinat, } \\
\text { Antonio }\end{array}$ & 56535155700 & 2014 & 4 & 2 & 26 & $\begin{array}{l}\text { Technical University } \\
\text { of Berlin }\end{array}$ & Germany \\
\hline 20 & Lister, Jane & 36190861800 & 2010 & 14 & 10 & 500 & $\begin{array}{l}\text { The University of } \\
\text { British Columbia }\end{array}$ & Canada \\
\hline
\end{tabular}

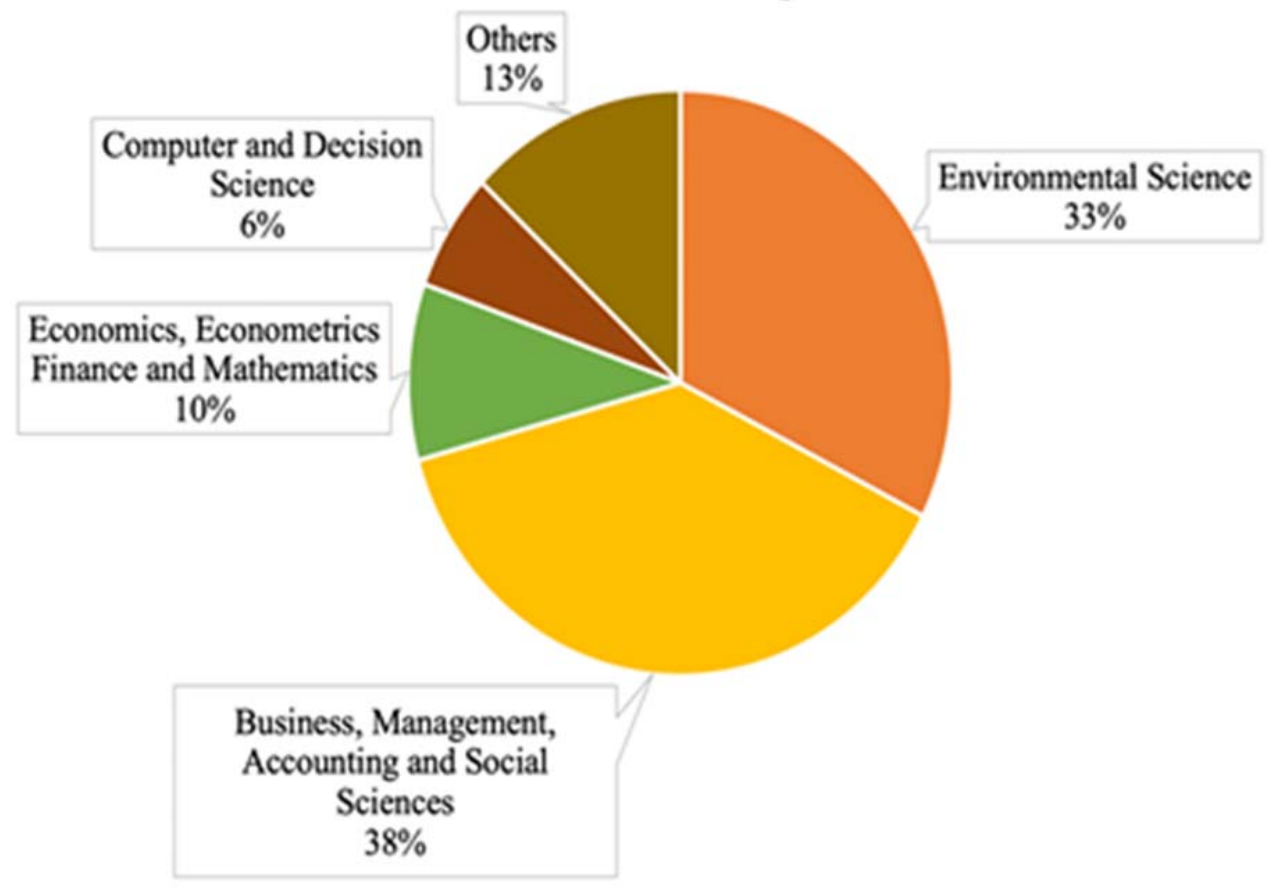

Figure 8. Diverse GSP research area under shipping domain

\subsection{Gsp Related Research Under Several Subject Areas}

This analysis took into consideration only articles that are relevant to GSP. Figure 8 presents the subtopic (depending on subject) weightage of GSP research. The majority of the publication derived from business, management, accounting, and social science perspective. Significantly, 33\% of the articles belong to "environmental science" subject category.
This demonstrates that business researchers are aware of environmentally friendly business operations. The notion "Green Shipping" is not a brand-new concept but, since 2016 it is evolving at a fast phase. Thus, more research is needed to generalize the finding on GSP implication in the organizational context. 


\subsection{Limitation of the Study}

This study envisaged only the Scopus database on green shipping for mapping research trends in the maritime industry. Since our interest was to anticipate GSP research patterns in international shipping only, green practice studies conducted in other industries such as construction, healthcare have not been considered. Search limited or narrowed down to "Green Shipping" and "GSP" in the international shipping industry within titles and abstracts may ignore potential studies on other fields related to green practices. Some articles might not show up because of utilizing different terms such as green initiative, green technology, low carbon, sustainability.

It is recommended to compare outputs from multiple scholarly databases, for example, Web of Sciences and Scopus, for future study. Features of the different databases may also reveal a different outcome. Exploiting multiple data sources to conduct bibliometric analysis will be useful for a more comprehensive study.

Another limitation of this study is, considering the articles published in English only. However, authors mostly publish articles in English to obtain maximum visibility; therefore, this bias is likely to impact a negligible degree [16]. Also, from each document, only the principal author has been given attention. Besides, Due to lack of information on author keywords, the Co-occurrence analysis analyzed $84 \%$ of keywords from 63 documents [9], [17]. Bibliometric analysis needs to be conducted regularly as the finding changes within a brief period with the availability of new articles on a particular research area [11]. Therefore, after few months, the study will be needed to get information on this topic's latest development. A multi-method data mining strategy is very much appreciated to get a better insight.

\section{Conclusion}

This study demonstrates a systematic synopsis of GSP research trends in the maritime sector based on Scopus's articles. Publication growth analyzed in this study indicates a rise in research trends in this field over the past two decades and anticipates a continued increment. Additionally, significant contributions from authors, top publishers, institutions, and countries have been compared with relevant systematic listings; The co-authorship link strength and authors' keywords were analyzed concurrently using the VOSviewer analytic tool. It is recognized that a few academic institutions and countries that have extensive involvement with shipping industry-related businesses are actively participating in research in this field with strong international collaborations. Researchers or institutes from other territories can extend their collaboration link with those institutes or countries to broaden their research alliances.

In this study, researchers embarked on a comprehensive literature review of GSP-related articles, current research developments, and identifying research gaps. The GSP theoretical approach is at its infancy in shipping; its concept and contents have not been established yet. It largely hinges on prevailing pollution conditions and government or territorial policy implications. Since IMO's implementation of MARPOL annexes, prevention of oil pollution was significantly improved, but air pollution persisted with elevated concern for which Annex VI of MARPOL was recently amended to address this issue. Hence, most of the existing research addresses practical problems mainly to abate air pollution, operational options, and technical measures as part of green shipping. The scope of green shipping is limited to port-to-port operations and MARPOL as the binding precedent. However, the application of GSP has to be throughout the life cycle of a ship, from shipbuilding, operation, logistics, repairs up to recycling. A few studies were carried out to construct GSP standards and their impact on shipping firms' environmental and economic performance. Besides technological research for reducing pollution, future research on GSP needs to propose a diverse solution and sophisticated evaluation system. Scholars from different institutes or countries can collaborate to provide practical recommendations for setting up GSP standards, green policy implications, and binding legislations for the sustainable maritime industry.

\section{Acknowledgement}

This research was funded by Universiti Teknologi Malaysia with “Geran Universiti Penyelidik” (GUP) Tier 2 Scheme, Vote No: Q.K130000.2656.16J42 for the financial support provided throughout the course of this research project. The publication fee for this paper is supported by using Vote No: Q.K130000.2856.00L57. The authors would like to express their greatest appreciation and utmost gratitude to the Ministry of Education Malaysia, Razak Faculty of Technology and Informatics, Azman Hashim International Business School and Universiti Teknologi Malaysia (UTM) for all the support towards making this study a success. 


\section{References}

[1]. Brooks, M. R., \& Faust, P. (2018). 50 Years of Review of Maritime Transport, 1968-2018: Reflecting on the Past, Exploring the Future (No. UNCTAD/DTL/2018/1).

[2]. Wan, Z., Zhu, M., Chen, S., \& Sperling, D. (2016). Pollution: Three steps to a green shipping industry. Nature, 530(7590), 275-277.

[3]. Lee, T., \& Nam, H. (2017). A study on green shipping in major countries: in the view of shipyards, shipping companies, ports, and policies. The Asian Journal of Shipping and Logistics, 33(4), 253-262.

[4]. Kim, S. (2015). Korea's shipbuilding industry goes into eco-friendly ship research. Retrieved from: http://www.greenplatform.re.kr/frt/center/news/wzinF ocus.do?pageMode $=$ View\&Id=22318 [accessed: 10 April 2021].

[5]. Doelle, M., \& Chircop, A. (2018). Decarbonizing International Shipping: Potential Roles of the IMO's Initial Strategy and the UN Climate Regime. Schulich School of Law, Dalhousie University.

[6]. Lun, Y. V., Lai, K. H., Wong, C. W., \& Cheng, T. C. E. (2015). Environmental governance mechanisms in shipping firms and their environmental performance. Transportation Research Part E: Logistics and Transportation Review, 78, 82-92.

[7]. Abdullah, A., Waemustafa, W., \& Mat Isa, H. (2017, July). Disclosure of Information in Company's Annual Reports: A Bibliometric Analysis. In Conference Proceedings (Vol. 2, No. 2, p. 66).

[8]. Roig-Tierno, N., Gonzalez-Cruz, T. F., \& LlopisMartinez, J. (2017). An overview of qualitative comparative analysis: A bibliometric analysis. Journal of Innovation \& Knowledge, 2(1), 15-23.
[9]. Anjum, H. F., Rasid, S. Z. A., Khalid, H., Alam, M. M., Daud, S. M., Abas, H., ... \& Yusof, M. F. (2020). Mapping research trends of blockchain technology in healthcare. IEEE Access, 8, 174244-174254.

[10]. Miau, S., \& Yang, J. M. (2018). Bibliometrics-based evaluation of the Blockchain research trend: 2008March 2017. Technology Analysis \& Strategic Management, 30(9), 1029-1045.

[11]. Martínez-López, F. J., Merigó, J. M., ValenzuelaFernández, L., \& Nicolás, C. (2018). Fifty years of the European Journal of Marketing: a bibliometric analysis. European Journal of Marketing.

[12]. Van Eck, N. J., \& Waltman, L. (2014). Visualizing bibliometric networks. In Measuring scholarly impact (pp. 285-320). Springer, Cham.

[13]. Hu, K., Wu, H., Qi, K., Yu, J., Yang, S., Yu, T., ... \& Liu, B. (2018). A domain keyword analysis approach extending Term Frequency-Keyword Active Index with Google Word2Vec model. Scientometrics, 114(3), 1031-1068.

[14]. Korstjens, I., \& Moser, A. (2017). Series: Practical guidance to qualitative research. Part 2: Context, research questions and designs. European Journal of General Practice, 23(1), 274-279.

[15]. Subedi, D. (2016). Explanatory sequential mixed method design as the third research community of knowledge claim. American Journal of Educational Research, 4(7), 570-577.

[16]. Hughes, D., Hughes, A., Powell, A., \& Al-Sarireh, B. (2019). Hepatocellular carcinoma's 100 most influential manuscripts: A bibliometric analysis. Int. J. Hepatobiliary Pancreat. Dis, 9.

[17]. Khudzari, J. M., Kurian, J., Tartakovsky, B., \& Raghavan, G. V. (2018). Bibliometric analysis of global research trends on microbial fuel cells using Scopus database. Biochemical engineering journal, 136, 51-60. 